\title{
Recorridos de La mujer sentada. Las tiras cómicas de Copi entre París y Buenos Aires.
}

\author{
The route of'The sitting woman'. The cartoons of Copi between \\ Paris and Buenos Aires
}

Isabel Plante ${ }^{1}$

\section{RESUMEN}

Las tensiones entre "gran arte" y "cultura menor" o entre producción visual e implicación política conformaron buena parte del entramado cultural de los años '60, años signados por el crecimiento de la industria cultural y por la radicalización política en diversos puntos del globo. En este contexto, el caso de Copi resulta clave por su actividad múltiple, que transitó con fluidez la narrativa, la dramaturgia y el humor gráfico. Residente en París desde 1962, Copi (1939-1987) creó para el semanario Le Nouvel Observateur el personaje que lo hizo conocido en Francia, La mujer sentada. Concebidas para el público masivo de la prensa modernizada de los años ' 60 , sus tiras interpelaron -desde un dislate corrosivo- a los sectores medios que se expandían a ambos lados del océano atlántico. Este artículo aborda precisamente esta suerte de vaivén geográfico y lingüístico mediado por la extranjería de Copi. Sin soslayar las especificidades del humor gráfico, pero tampoco fenómenos culturales más amplios de los años '60 como la internacionalización de la cultura urbana y difuminación de los límites del campo artístico.

Palabras Clave: Copi. Humor gráfico. Cultura en los años sesenta. Arte y extranjería. Buenos Aires-París.

\section{ABSTRACT}

During the 1960' -those years marked by the growth of cultural industry and political radicalization in diverse points of the world- the cultural field was shaped by the tensions between 'Art' and 'minor culture' or between visual production and political commitment. In this context, the multiple activity of Copi makes him a key case since it fluently traveled trough narrative writing, dramaturgy and graphic humor. Living in Paris since 1962, Copi created for the newspaper Le Nouvel Observateur the character that made this argentine artist famous in France, La Femme Assise (The sitting woman). Conceived for the massive audience of the modernized press of the 1960', his strips questioned -with corrosive nonsense- middle sectors in expansion at both sides of the Atlantic Ocean. This paper tackles precisely with this sort of geographic and linguistic swinging mediated by Copi's foreignness. This without eluding nor the graphic humor's specificities, nor larger cultural phenomenon of the 1960's like the internationalization of the urban culture and the fading of the borders of the artistic fields.

Keywords: Graphic humor. 1960. Culture. Art and foreignness. Buenos Aires-Paris.

${ }^{1}$ Instituto de Altos Estudios Sociales, Universidad Nacional de San Martín. 


\section{Imagen 1 - "La Femme Assise"}

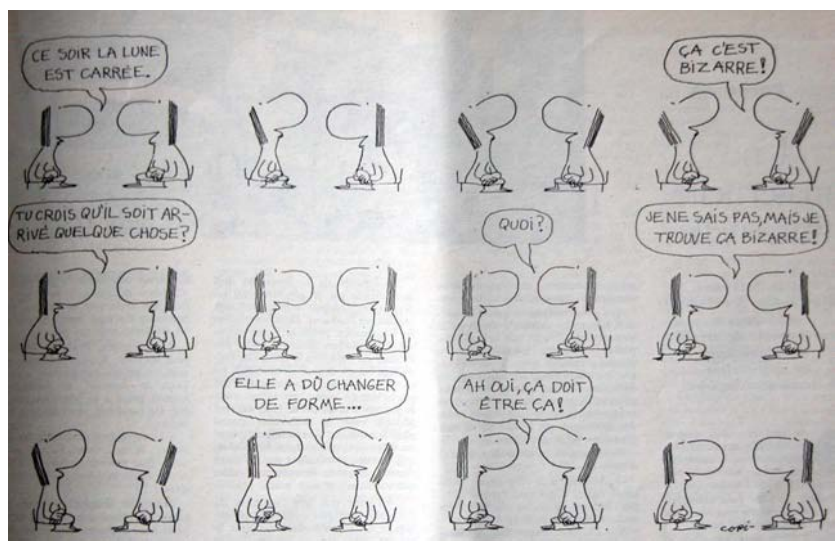

Fonte : Copi (1968, p.29).

Esta fue la tira que Copi (Raúl Natalio Damonte, 1939-1987) publicó inmediatamente después del Mayo francés de 1968. Si bien durante los casi dos meses de la revuelta, suspendió su tira semanal de Le Nouvel Observateur, el 26 de junio La Femme Assise volvió a las páginas de ese semanario gauchiste. Esta vez, eran dos las mujeres sentadas que, una frente a la otra, sostenían un diálogo desconcertante. En la primera viñeta, la mujer de la izquierda anuncia que esa noche la luna se ve cuadrada. Con la cadencia casi ralentada de esos diálogos, siempre mínimos, que caracterizaban la tira, las dos viñetas siguientes muestran a una de ellas dirigiendo la mirada hacia arriba. Luego miran ambas por encima de sus cabezas y la otra mujer afirma: "Si, es raro". A lo que la primera responde: “¿Crees que habrá pasado algo?”. Otra viñeta las muestra enfrentadas mirándose en perfecta simetría; en la siguiente, “¿Qué?". "No sé, pero me parece raro esto". Dirigen otra vez la mirada hacia arriba al unísono. Y luego el diálogo concluye: "Debe haber cambiado de forma". "Si, debe ser eso". El último recuadro muestra a las mujeres sentadas con un pequeñísimo cambio en la expresión de sus ojos (una línea horizontal en vez de un punto) que denota satisfacción de haber dilucidado el extraño fenómeno lunar.

La explicación tautológica del cambio de forma resuena, por un lado, con la similitud de los dos personajes de la tira, que por momentos parecen el resultado del desdoblamiento especular de la mujer sentada. Por otro lado, esas igualdades contrastan con la diferencia en la silueta de la luna, comunicada a los lectores por intermedio de la palabra y no mediante imágenes, a lo largo de dibujos sucesivos que muestran cambios mínimos. Algo había cambiado de manera inesperada, algo que formaba parte tanto del entorno cotidiano como del sistema planetario. Si la luna se asocia a lo femenino, la tira insinuaba que aunque a estas mujeres siempre sentadas les resultara poco trascendente, el fenómeno gravitaba sobre sus cabezas. 
Residente en París desde 1962, Copi tuvo una efímera actividad como artista visual en la ciudad-luz ${ }^{2}$. Su labor como dibujante humorístico primero y más tarde como teatrista y escritor le deparó, en cambio, su consagración artística. En entrevistas, él mismo relató que a los 22 años fue a París a ver teatro y luego decidió quedarse. Cuando su padre le suspendió los envíos de dinero, en el verano europeo de 1963, comenzó a vender dibujos en el Pont des Arts. El editor Jean-Jacques Pauvert trabajaba no muy lejos, allí vieron sus trabajos y lo pusieron en contacto con Serge Lafaurie quien preparaba un nuevo semanario, Le Nouvel Observateur ${ }^{3}$.

En 1964 Copi creó para este renovado periódico de izquierda el personaje que lo hizo conocido en Francia (mucho más que el resto de los argentinos de París), La mujer sentada ${ }^{4}$. Más tarde también publicó tiras en revistas francesas para público adulto como Hara Kiri (1960) y Charlie Mensuel (1969), que contribuían a la renovación gala de la producción de historias dibujadas junto con las posteriores L'Echo des Savantes (1972) o Métal Hurlant (1975). Algunas de estas tiras se republicaron con celeridad en la prensa argentina. En 1965 aparecieron unas pocas en Primera Plana, a las que siguieron otras en La Hipotenusa -la revista de humor gráfico editada en 1967 por Helvio Botana, tío de Copi-. Luego, una o dos tiras en cada número de Literatura Dibujada -la ambiciosa publicación de historietas que Oscar Masotta lanzó a fines de $1968^{5}$ - y por último algunas más en la revista de actualidades Atlántida. En 1968 se tradujo al castellano el libro que había compilado buena cantidad de tiras aparecidas en Le Nouvel Observateur, Les poulets n'ont pas de chaise (Editions Denoël, 1966). La edición local de Jorge Álvarez, Los pollos no tienen sillas, con sus 57 tiras representó la llegada más contundente de la producción humorística de Copi a la Argentina ${ }^{6}$.

\footnotetext{
${ }^{2}$ En una entrevista de 1966, Copi cuenta que pintaba y vendía sus dibujos, pero que la técnica experimental hacía que al poco tiempo no quedara nada de esas obras. Jacquelin Wester y Bernard Bouthier, Copi (1966), cortometraje de 16 minutos, archivos del Institut National d'Audiovisuel, Francia. Según Daniel Link, realizaba dibujos por medio de acciones como lanzar bombitas de agua llenas de tintas de diversos colores contra una superficie de papel. Según otros testimonios, también realizaba dibujos con tiza en las veredas parisinas y vendía collages. Frédéric Martel (1999, p. 90).

3 "Cada uno debe inventarse sus historias. Entrevista realizada por Libération" (TCHERKASKI, 1998, p. 122. Le Nouvel Observateur, semanario de información general, comenzó a publicarse el 19 de noviembre de 1964 como una versión renovada de L'Observateur politique, économique et littéraire (France Observateur entre 1964 y 1964), que había sido fundado en 1950 por integrantes de la Resistencia Francesa como Gilles Martinet, Roger Stéphane, Claude Bourdet y Hector de Galard. Ese periódico se había destacado por su tono polémico en relación a las guerras coloniales y sus denuncias de la tortura implementada en Argelia. A comienzos de 1964 tenía problemas financieros. El industrial Claude Perdriel y el periodista Jean Daniel lo relanzaron conservando su perfil opositor y su sensibilidad de izquierda. La primera tirada fue de 100.000 ejemplares y hacia 1974 , ascendía a 400.000 ejemplares.

${ }^{4}$ Confirmado informaba en mayo de 1965 que los lectores de Le Nouvel Observateur eran unos 300.000. "Argentinos en París", Cofirmado n. 1, 7/5/1965, p. 26. Desde mediados de los años '60, se han editado sus tiras en diversos libros: Humour secret. 1964; Les poulets n'ont pas de chaise. Paris, 1966; Le dernier salon où l'on cause. Paris, 1973 ; Et moi, pourquoi j'ai pas de banane? Paris, 1975 ; Du côté des violés. Paris, 1976 ; Les vieilles putes. Paris, 1977 ; La femme assise. Paris, 2002 ; Un livre blanc. Paris, 2002.

${ }^{5}$ Se publicaron sólo tres números de LD entre noviembre de 1968 y enero de 1969, que incluyeron Peanuts, Flash Gordon, Mort Cinder de Oesterheld y Breccia, El rey petiso de Otto Soglow, Dick Tracy, Valentina de Guido Crepax. Los dos primeros contaron con una tira de Copi traducida al castellano.

${ }_{6}^{6}$ En los estudios recientes sobre la producción humorística de Copi, este libro es considerado una compilación de Álvarez, sin referencia alguna a la edición francesa previa.
} 
Imagen 2 - Los pollos no tienen sillas. Buenos Aires, Jorge Álvarez, 1968. Portada.

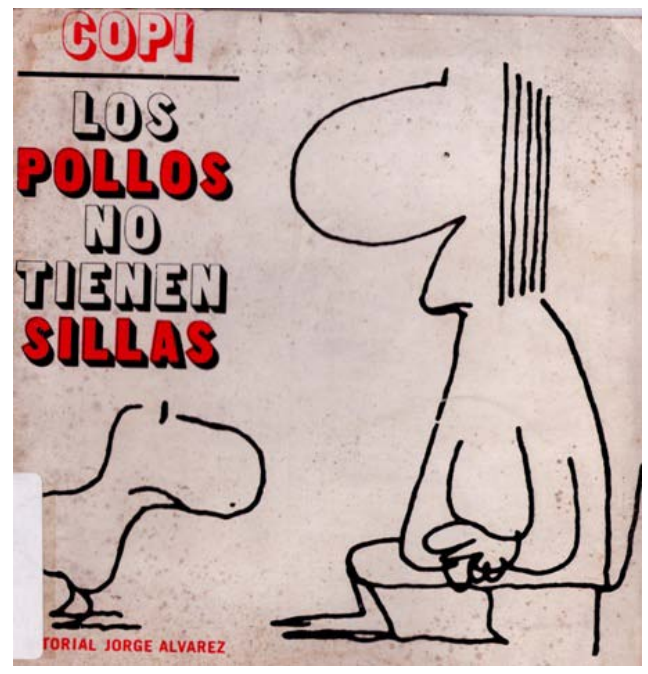

Fonte: Copi (1968).

El estatus nacional de la obra de Copi resulta, por lo menos, ambiguo. Sin embargo, los estudios locales tienden a tratarlo como un autor argentino sin problematizar sus recorridos geográficos, el uso particular que hizo de la lengua francesa tanto en su producción escrita, teatral como humorística, ni considerar la capacidad del humor gráfico de interpelar a públicos de nacionalidades distintas. Este artículo aborda precisamente esta suerte de vaivén geográfico y lingüístico mediado por la extranjería de Copi. Sin soslayar las especificidades del humor gráfico y las de su circulación, pero tampoco fenómenos culturales más amplios de los años '60 como la internacionalización de la cultura urbana y difuminación de los límites del campo artístico.

Las tensiones entre "gran arte" y "cultura menor", entre producción visual e implicación política, o entre práctica artística y crítica institucional conformaron buena parte del entramado cultural de los años '60, años signados por el crecimiento de la industria cultural y por la progresiva radicalización política en diversos puntos del globo. Para Gilles Deleuze y Felix Guattari (2001), esas tensiones tenían su punto de fuga en el Pop en tanto estrategia orientada al "uso menor" de la "alta cultura". Hacia 1975, en defensa de lo que denominaban "literatura menor" estos autores alegaban que el Pop representaba la hibridación y por ende el final del arte, la literatura y la música en tanto producciones modernas. En este contexto, el caso de Copi resulta clave por su actividad múltiple, que transitó con fluidez la narrativa, la dramaturgia y el humor gráfico. Pero también por el uso del francés en vez de su lengua materna para producir la mayor parte de su obra.

Hacia mediados de los años '60, cuando Pierre Bourdieu realizó sus estudios de público de museos y definió la noción de campo cultural, las exhibiciones de arte convocaban una cantidad inédita de visitantes y la arquitectura institucional de ese campo era cuestionada por una serie de artistas y prácticas. Por un lado, no fueron escasos los cruces entre la elaboración de obras de arte 
y producciones visuales difícilmente enmarcables dentro de los límites tradicionales de las bellas artes. El diseño colectivo y la impresión de afiches por parte de artistas y estudiantes (entre los cuales contaron los argentinos Julio Le Parc, Rómulo Macció o Antonio Seguí) en el célebre Atelier Popoulaire de 1968 es tal vez el caso más evidente en este sentido.

Por otro lado, dentro del ámbito de las artes visuales un movimiento de vocación masiva como el cinetismo, por ejemplo, apostaba a una producción móvil, múltiple y atractiva que no requería mayores competencias artísticas y resultaba cada vez más convocante. Dos exposiciones de 1967, una en París y otra en Buenos Aires, atrajeron una cantidad de público formidable que la crítica comentó en algunos casos con entusiasmo y, en otros, con desconfianza: Lumière et Mouvement en el Musée d'Art Moderne de la Ville de Paris, y la retrospectiva del argentino Julio Le Parc en el Instituto Torcuato Di Tella, que atrajo más de 150.000 personas (PLANTE, 2010). Del mismo modo, la exposición parisina de arte e historietas Bande Désinée et figuration narrative (que incluyó obras de Antonio Berni) realizada también en 1967 convocó la impactante cifra de 350.000 visitantes (COUSTÉ, 1968, p. 44-49). Si se tiene en cuenta que hacia 1965 la tirada de Le Nouvel Observateur era de unos 300.000 ejemplares, esas cantidades resultan aún más significativas. Permiten vislumbrar que la tradicional imagen de las artes visuales como privativas de una élite y la historieta como patrimonio exclusivo de una cultura de masas no parece ajustarse a esos años en los que el consumo cultural adquirió volúmenes inéditos y la "contracultura" reutilizó medios y géneros diversos. En tanto género definido en el riñón de la "galaxia Gutenberg", la historieta se constituyó como otro espacio posible para la contestation (utilizo un término caro al París posterior a mayo del '68).

Dentro de este panorama de la izquierda francesa, en tanto "argentino de París" multifacético y satírico Copi ocupó un lugar particularmente productivo. ¿Fue innovador el humor gráfico que produjo en esos años? ¿En qué aspectos? ¿De qué modos articuló lo visual y lo escrito para detonar la risa o la sorpresa? ¿Es posible restituir los sentidos de sus tiras en el momento de su primera publicación? Al igual que cualquier producción cultural, las tiras de Copi no constituyen simples 'documentos de época' sino que articulan representaciones mediadas tanto por cuestiones técnicas, como por especificidades del género artístico y del proyecto estético. Tal vez precisamente por esta razón, con las herramientas interpretativas adecuadas pueden encontrarse en ellas trazos o restos del espesor cultural de una época.

Si bien su producción gráfica no seguía de cerca los acontecimientos sociales o políticos contemporáneos, como suele hacer la caricatura política, estuvo en muchos aspectos empapada del entorno francés de esos años. Esa cualidad esmerilada puede percibirse, por ejemplo, en la tira que elegimos para comenzar este texto puesto que sabemos su fecha de publicación y esto nos permite restituir los vínculos con un contexto específico de producción. En ese sentido, sin pretender agotar la variadísima temática de sus comic, veremos que en momentos de la emergencia internacional de las escenas política y cultural de América Latina, Copi ironizó en 
algunas de sus historietas (y mucho antes que en su novela La guerra de los putos) con el imaginario desplegado alrededor de Latinoamérica y la Amazonia como lugar utópico.

\section{La historieta como género transnacional y el problema de la lengua}

Por supuesto, Copi no era el único migrante desde el Plata al Sena. No fueron pocos los artistas, escritores, teatristas y músicos que viajaron a París desde la posguerra. La marginalidad del campo artístico porteño en el mapa mundial fue un motivo central para la partida pero no fue el único. Desde mediados del siglo $\mathrm{XX}$, la tradición inmigratoria argentina viró en una emigración constante de científicos e intelectuales por motivos políticos, económicos y profesionales. La imposición de proyectos político-culturales durante el primer peronismo y la política represiva de Onganía a partir de 1966 propulsaron el fenómeno conocido como "fuga de cerebros"7. En el caso de la literatura, Julio Cortázar arribó en 1951 y Juan José Saer en 1968, por nombrar dos escritores que continuaron produciendo en su lengua materna. En teatro, Jorge Lavelli, Gerôme Savary y Alfredo Rodríguez Arias. Entre los artistas visuales, París constituyó el destino preferido durante la posguerra ${ }^{8}$

Superpuesta con una colectividad latinoamericana más amplia, durante los años '60 hubo en Francia una comunidad argentina que se definió a sí misma y fue vista desde Buenos Aires como los "argentinos de París". En su novela L'Internationale Argentine (1988), Copi ofrece una imagen (disparatada) de la presencia nacional fuera del país. La organización ficticia que da nombre al libro se propone "coordinar las acciones en que participan de manera desordenada todos los argentinos que viven en el extranjero". Saturado de la locura de sus compatriotas, el Copi de la ficción escapa a Buenos Aires: “¡En París hay demasiados argentinos!”.

Copi fue uno de los integrantes de esta colectividad que se asimilaron con mayor rapidez, tal vez, debido al manejo de la lengua francesa adquirido a través de su padre y durante su adolescencia en Francia ${ }^{9}$. A excepción de la novela La vida es un tango (1979) y de la pieza de teatro Cachafaz (1981), concebidas en castellano, Copi escribió toda su obra en francés (los diálogos de sus historietas fueron escritos, por supuesto, en ese idioma). Judith Podlubne y Alberto Giordano afirman en este sentido que la crítica francesa considera que Copi escribe en una lengua que

\footnotetext{
${ }^{7}$ Entre 1960 y 1970 se calcula que se fueron del país 128.217 personas y entre 1970 y 1980, 236.138. Marina Franco (2008).

${ }^{8}$ Entre 1948 y 1954: Alicia Peñalba, Marta Traba, Lea Lublin, Miguel Ocampo, Damián Bayón, Alberto Greco y Emilio Pettoruti. Entre 1958 y 1966, una tanda más nutrida de artistas: Martha Boto, Luis Tomasello, Gyula Kosice, Julio Le Parc, Horacio García Rossi, Gregorio Vardánega, Eduardo Jonquieres, Francisco Sobrino, Hugo Demarco, Armando Durante, Antonio Berni, Antonio Seguí, Rómulo Macció, Lea Lublin nuevamente, Nicolás García Uriburu, Juan Stoppani, Delia Cancela y Pablo Mesejean, entre otros.

${ }^{9}$ Los testimonios de Copi sobre su vida varían. En un texto autobiográfico destinado a prologar una novela que nunca se publicó, Río de la Plata, dice haber llegado a París en 1952 cuando, mientras su padre era cónsul de Uruguay en Reims, Copi cursó un año de la escuela. Copi (1990, p. 81-91). En una entrevista dice haber pasado dos años en París entre sus catorce y dieciséis años, lo que correspondería al período 1953 -1955. “Un argentino de París. Entrevista de Raquel Lineberg”, en José Tcherkaski (1998, p. 113).
} 
parece extranjera (PODLUBNE; GIORDANO, 2000, p. 321-341). Sin embargo, a pesar de que no haya reivindicado su nacionalidad (ni su sexualidad) en términos de identidad, obras como Eva Perón (1969), El uruguayo (1973), La Internacional Argentina o La vida es un tango remiten, de modo paródico o camp (SONTAG, 1964), al mundo rioplatense. En esta dirección, Daniel Link propone una interpretación más aguda que integra la cuestión de la lengua con el sentido de identificarse como "argentino de París".

La propuesta de Copi es sencilla: se trata de oponer al Estado-Nación y sus ficciones guerreras la idea de comunidad (posnacional y, al mismo tiempo, imposible). [...] Es, además, el tema de La internacional argentina, tal vez su novela más dogmática. $Y$ es algo que recorre toda su obra bajo la forma de la apropiación lingüística: "He preferido colocarme en el no man's land de mis ensoñaciones habituales, hechas de frases en lengua italiana, francesa y de sus homólogas brasileña y argentina, entrecortadas con interjecciones castellanas, según la sucesión de escenas que mi memoria presenta a mi imaginación", escribió Copi en un manuscrito que se guarda en la abadía normanda de Ardenne donde funciona el instituto francés de manuscritos.Copi, que es un argentino de París ( $y$ no un argentino en París, como nunca fue un parisiense o un uruguayo en Buenos Aires) rechaza la identificación con una lengua, con un Estado, al mismo tiempo que rechaza todos los demás trascendentales. Propone una estética trans: transnacional, translingüística y transexual, en el sentido en que lo trans debe entenderse, como el pasaje de lo imaginario a lo real. (LINK, 2008).

En una entrevista, Copi hacía notar que para el público francés su tira semanal resultaba una caricatura propia de la izquierda francesa, y acotaba: “qué sabrán ellos de la influencia que yo puedo tener de Landrú o de Lino Palacio?”"10. En efecto, antes de dejar Buenos Aires Copi había sido colaborador del semanario humorístico Tía Vicenta, dirigido por Landrú desde $1957^{11}$, y tanto las tiras de Le Nouvel Observateur como la producción gráfica de Copi difundida en otros periódicos fueron realizadas con un trazo simple e incluso deliberadamente torpe, en la línea de

\footnotetext{
${ }^{10}$ Entrevista por José Tcherkaski (1998, p. 27) Un detalle interesante en relación con el vínculo entre la producción gráfica de Copi y la de Landrú es que éste incluía un signo de admiración final en su firma y Copi utilizó hasta la exasperación este recurso enfático en los diálogos que sus personajes sostienen.

${ }^{11}$ Hacia mediados de los ‘50, en los años anteriores a la difusión de la televisión, se editaban en Argentina unas setenta publicaciones dedicadas a la historieta, algunas de las cuales tenían tiradas muy cuantiosas (Patoruzito: 300.000 ejemplares, Misterix: 250.000, Intervalo: 280.000). 1957 fue un año clave: no sólo aparecieron Hora Cero (donde se publicó por primera vez El Eternauta), Frontera (ambas fundadas por Oesterheld) y D'Artagnan, sino también Tía Vicenta. Judith Gociol y Diego Rosemberg (2000). Véase también Vázquez Lucio (1985). Pablo de Santis afirma que La Mujer Sentada ya estaba definida como personaje Tia Vicenta. Según nuestro rastreo hemerográfico, una tira de Copi publicada en el n. 67 $(18 / 11 / 58)$ la presenta una protagonista femenina que aparece sentada, viñeta tras viñeta, pero no desarrolla ni los juegos gráficos, ni el humor sutil y por momentos ácido que caracteriza al personaje del Nouvel Observateur. Pablo De Santis (1998).
} 
Oski o Landrú ("humor tonto", tal como lo denomina Oscar Steimberg" ${ }^{12}$ ). Sus dibujos no presentaron la complejidad visual de historietas narrativas como El Eternauta o Valentina (una historieta italiana con la que compartió las páginas de la revista local Literatura Dibujada). Copi utilizó como recursos humorísticos la síntesis gráfica, la inmovilidad de los personajes y el efecto sorpresa disparado en algunos casos desde lo visual y, en otros, por los diálogos insólitos.

Imagen 3 - Literatura Dibujada n. 1, noviembre 1968. Portada con dibujo de Valentina de Guido Crepax

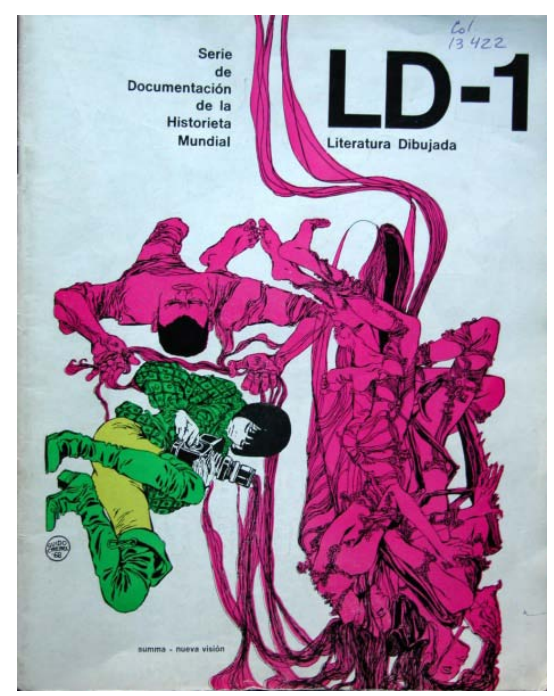

Fonte: Copi (1968).

Concebida para el público urbano y masivo de la prensa modernizada de los años ‘ 60 , de la que Le Nouvel Observateur y L'Express resultan ilustrativas del caso francés, en su recepción la tira de Copi tuvo ciertos puntos en común con Mafalda, por ejemplo, que también fue publicada por primera vez en $1964^{13}$. En el caso de esta historieta de Quino aparecida en las páginas de Primera Plana, si bien para el público argentino representa aun hoy una típica familia de clase media, también podría identificarse con los sectores medios franceses (a esto contribuye la presencia del automóvil familiar marca Citroën, que Roland Barthes señala como uno de los emblemas de la Francia de posguerra $)^{14}$. Al igual que el personaje de Quino, La mujer sentada interpeló -desde un

\footnotetext{
12 "Steinberg, especialmente, inaugura procedimientos que definen al humorista gráfico como alguien que juega, que no dice, que no sabe. En sus dibujos se produce la caída del autor ideal, omnisciente como un narrador naturalista". Oscar Steimberg (2001).

${ }^{13}$ Sobre la modernización de la prensa véanse, en el caso francés, Kristin Ross (1995). Para el caso argentino de Primera Plana, véanse Alvarado y Rocco-Cuzzi (1984, p. 27-30) y Oscar Terán (1993).

${ }^{14}$ Roland Barthes (2003, p. 154-156). Mafalda tuvo una difusión internacional temprana. Fue traducida por primera vez en 1968, al italiano, en un libro que llevó por título Mafalda, la contestataria y contó con un prólogo sin firma escrito Umberto Eco. Oscar Steimberg ha interpretado a Mafalda en su interpelación a los sectores medios. "Diestra narración gráfica, vehículo de una corriente de opinión compartida por un público amplio, portadora de un lenguaje verbal agradablemente culturizante, Mafalda atrapa a sus lectores con la ilusión de un ejercicio de lectura anticonformista, fundado en una ideología que reniega del establishment. Pero la agilidad y la transparencia de sus juegos conceptuales se fundan en un repertorio de tipos humanos determinado por un elemental Medio Ambiente, en el que campean las caracterizaciones sociales del sentido común". Oscar Steimberg (1977). Para una historia pormenorizada de Mafalda, véase Judith Gociol y Diego Rosemberg, (2000).
} 
dislate por momentos corrosivo- a los sectores medios que se expandían a ambos lados del océano ${ }^{15}$.

La actividad teatral de Copi no se limitó a la dramaturgia. Al poco tiempo de llegar a París, comenzó a actuar con el Grupo Pánico, creado por Alejandro Jodorowsky, Fernando Arrabal y Roland Topor, al que más tarde se sumó Jorge Lavelli quién, a su vez, pocos años después asumió la dirección de algunas obras teatrales de Copi. También actuó en Grand Magic Circus dirigido por otro argentino de París, Jerôme Savary, y fue parte por un tiempo del Grupo Tsé, creado por Alfredo Rodríguez Arias en Buenos Aires y relocalizado en París en 1969. Al Grupo Tsé se lo vincula al pop y la propuesta del Grupo Pánico estaba ligada al surrealismo y al teatro de la crueldad en la línea de Antonin Artaud. Por su parte, La Femme Assise ("La mujer sentada") era el título de una novela de Guillaume Apollinaire (LINK, 2011), el inventor del término "surrealismo" que algunos años más tarde retomó André Breton. Pero más allá de estos eventuales nexos, el humor "tonto" de Copi nos hace pensar en ciertos puntos en común con el teatro del absurdo, en la versión de Eugène Ionesco ${ }^{16}$.

Este movimiento teatral de posguerra se define en la puesta en evidencia de lo artificial de las ideas corrientes sobre la realidad, en particular del carácter convencional del comportamiento y del lenguaje en tanto conjunto de clichés, fórmulas vacías y slogans. La postergación del diálogo y la acción, una de las características formales que señala Osvaldo Pelletieri (1993) para este teatro, constituye en efecto un recurso reconocible en las tiras de Copi tal como veremos en el próximo apartado.

En este punto, quisiéramos remarcar que el origen de La cantante calva, está directamente ligado al aprendizaje de una lengua extranjera por parte de Ionesco. Francófono, comenzó a escribir esta obra paradigmática (estrenada en 1950 y publicada por primera vez en francés en 1952), a partir de la transcripción del manual que utilizaba para estudiar inglés. Este libro poblado de afirmaciones obvias (del tipo: el techo está arriba y el suelo, abajo) incorporaba personajes como Mr y Mrs Smith en diálogos que de tan obvios resultaban ridículos. Verdades axiomáticas, perogrulladas que no son tan evidentes si no se maneja esa lengua (ESSLIN, 1966). En La cantante calva, Ionesco extremó ese uso del lenguaje. Parte de las situaciones cómicas están dadas porque este matrimonio se informa de cosas que ya deberían saber: por ejemplo, el personaje de Mrs. Smith le decía a Mr. Smith que él era su marido y que tenían varios hijos y vivían en las proximidades de Londres. La poética del absurdo, al difuminar los límites de la lógica, avanza sobre el sentido común y, según los casos, genera un sin sentido placentero o angustiante.

\footnotetext{
${ }^{15}$ Eric Hosbawm se refiere a los '60 como "los años dorados" durante los cuales el excedente económico volcado a la cultura era inédito, del mismo modo que el proceso de urbanización a nivel mundial. Estos son dos de las condiciones de posibilidad de esa "joven cultura industrial" que, según Link, caracteriza la década. Eric Hosbawm (1998). Daniel Link (2005).

${ }^{16}$ Tanto la obra de Beckett como la de Ionesco habían llegado a Buenos Aires a mediados de los años '50, y entre fines de esa década y comienzos de la siguiente, hubo una primera tanda de absurdistas porteños. De modo que no es inviable que Copi ya estuviera familiarizado con esa corriente antes de dejar la Argentina.
} 
Tal como vimos en la tira del comienzo sobre los cambios de forma de la luna, Copi parece haber trabajado en su producción gráfica de modo similar: al machacar sobre lo evidente, genera un extrañamiento de la cotidianidad que mueve a la risa (o a la sonrisa). En efecto, entre sus recursos humorísticos cuentan el comentario obvio y el uso escueto del idioma francés. En este sentido, es posible pensar en un "uso menor" de la lengua facilitado por la extranjería.

\title{
La mujer sentada y la narración permanente
}

\begin{abstract}
Un día Michael llega muy excitado: ha tenido una idea fantástica para que hablen de él los periódicos romanos: va a pintar de rojo el agua de la fuente de Santa Maria in Trastevere (basta con echar un colorante), tirará allá a Pierre vestido de Jesucristo, va a ser un escándalo increíble. Pierre se niega, por miedo a resfriarse. Michael se pone furioso, nos acusa de insolidaridad (no essere solidario) con sus proyectos. Yo ya estoy harto de Michael, desde que está en Roma se cree que tiene patente de corso para todo, ha cogido el mismo trip de los artistas: cualquier estupidez que inventan debe atraer inmediatamente la admiración y el apoyo de su entorno.
\end{abstract}

Copi, Le bal des folles (1977).

Este párrafo proviene de $E l$ baile de las locas, una novela de Copi publicada en francés en 1977. Por medio de una proliferación narrativa precipitada, el libro relata las múltiples peripecias del personaje Copi, un humorista gráfico y 'una loca'. Además de incluirse a sí mismo dentro de la ficción, Copi solía incorporar otros nombres reales (en esta novela incorpora a dos humoristas gráficos amigos suyos, Wollinski y Sempé). ${ }^{17}$ Así, la referencia burlona a la idea de colorear las aguas de la fuente italiana alude, con toda probabilidad, a las coloraciones verdes del Gran canal de Venecia (entre otras aguas de diversos puntos del globo) con las que se había destacado Nicolás García Uriburu, otro artista argentino radicado también en París. Pero si bien la novela tiene momentos hilarantes, no debemos entender este guiño como una broma simple. Más allá de las simpatías o antipatías personales que pudiera haber entre ambos "argentinos de París", los celebrados happenings y acciones artísticas no revestían interés estético para Copi. En este sentido, Daniel Link sostiene con tino que el vínculo entre acción y narración es uno de los hilos conductores de su producción:

La obra de Copi, podría decirse, constituye una investigación sistemática de los modos de la acción en el arte (tanto en lo que se refiere al universo representado como al acontecimiento estético: hay

\footnotetext{
${ }^{17}$ Copi (1977, p. 14). El primero trabajaba en la revista de humor gráfico Hara Kiri y el segundo en L'Express.
} 
que recordar las palabras de Copi, para quien "el happening es algo que me hace sudar frío. Es como si alguien entrara aquí y meara en la botella. Es odioso y vacío de historia. El happening es lo que no sucede").

En los comics de Copi, todo lo que podría suceder ya ha sucedido, en sus relatos todo va a suceder y en sus obras de teatro todo está sucediendo en un vértigo que no anula la temporalidad sino que la proyecta a una dimensión utópica donde el pasado, el presente y el futuro adquieren relaciones nuevas.

Leída en la intersección del comic, la ficción narrativa y el teatro (aspectos en los cuales se funda por igual su prestigio), la obra de Copi interroga centralmente la noción de acción (dramática y narrativa). ${ }^{18}$

Si Oscar Masotta entendía a la historieta como literatura dibujada, probablemente se debió al apego de la historieta por la narración ${ }^{19}$. Sin embargo, aunque cada uno de los tres números de Literatura Dibujada incluyó hasta dos tiras de Copi de página completa, tanto en sus recursos formales como en sus personajes e historias, éstas distan de la historieta narrativa que durante los años '60 tuvo un gran desarrollo tanto en Argentina como en Europa ${ }^{20}$.

La carencia argumental del happening estaba en las antípodas de su producción literaria y teatral, estructurada como encadenamiento acelerado de acontecimientos, muchos de ellos truculentos (en El Baile de las locas, los mellizos que Copi adopta son devorados por los tiburones). En algunos casos, las historias dibujadas de Copi también relatan sucesos catastróficos como ocurre con los cuentos, novelas y piezas de teatro, pero esas calamidades forman parte de un pasado. Las tiras no multiplican sucesos a borbotones, sino que manejan una cierta economía de la acción. Dentro de las viñetas sucede poco: suelen ser dos o tres personajes que mantienen un diálogo en un solo lugar, apenas esbozado con algún mueble u objeto. César Aira ubica los comic de Copi en la prehistoria de su producción y los analoga a los relatos cortos publicados en $1978^{21}$, a los que denomina "cuentos-comic". Dice de estos relatos:

Ante su visualidad exacerbada y sus complicadas catástrofes, uno se pregunta si no serán comics que Copi no se tomó el trabajo de dibujar y entonces escribió. El dibujo de Copi, tan escueto y razonable, no condesciende al cataclismo. Pero el cataclismo es necesario en sus

\footnotetext{
${ }^{18}$ Esta es la hipótesis alrededor de la cual Link organizó el seminario de doctorado "Copi: modos de la acción literaria", dictado en la Facultad de Filosofía y Letras Universidad de Buenos Aires durante 2007. Cito el programa. De este autor, véase también "Fuera de serie: Eva Perón de Copi", en Seminario Internacional "Poéticas do Inventàrio: coleções, listas, séries e arquivos", Universidade Federal de Minas Gerais. 2007, mimeo.

${ }^{19}$ Más que al poder legitimador de las letras (análogo en todo caso al de la pintura). Me refiero a la afirmación un tanto simplificadora de Laura Vázquez (2010). Véase Oscar Masotta (1969, p. 9-10).

${ }^{20}$ Hasta los '60, las revistas de historietas como Spirou y Tintín estuvieron orientadas al público infantil. En 1959 Pilote, una suerte de versión francesa de la norteamericana $\mathrm{Mad}$, comenzó a publicar Asterix, que atrajo lectores adolescentes. Pocos años más tarde las historietas encuentran un público adulto y se pueblan con personajes sexy como Valentina. Pablo De Santis (1998). Sobre el caso argentino, véase Oscar Steimberg (2000, p. 533-548).

${ }^{21}$ Reunidos en Copi (1978).
} 
historias. De ahí que en ocasiones escribir haya sido lo más económico para él ${ }^{22}$.

Si bien Aira encuentra ciertas analogías entre las producciones narrativa, dramática y gráfica de Copi, para comprender las tiras cómicas con mayor precisión es necesario introducir especificidades de género. Es sobre esas convenciones y expectativas que Copi opera sobre para generar efectos humorísticos. Sus tiras responden a las características del comic, el primer formato que adoptó el humor gráfico en la prensa de masas de fines del siglo XIX: tiras breves, de cuatro o cinco cuadros, que resumen una situación con pocos elementos y palabras y que, por lo general, cultivan "la miniatura, la elipsis, la sorpresa" ${ }^{23}$. A diferencia de la historieta narrativa, esta historieta humorística utiliza un dibujo sintético y más bien caricaturesco. Concebidas en el marco de una lectura ágil, la situación planteada debe comprenderse con un golpe de vista. De este modo, por lo general el fondo de la escena se compone con lo mínimo indispensable para seguir la secuencia. Mientras la historieta narrativa tolera en su lectura varias direcciones señala Pablo De Santis- en el humor gráfico "la atención viaja como una flecha del primero al último cuadro". Pero el uso que Copi hace de esta tipología no se ajusta a esta caracterización pues resulta, paradójicamente, una narración acompasada de tiempos ralentados.

Algo similar ocurre con la definición del personaje central. Pensando en la Ramona de Lino Palacio, Alan Pauls (1995, p.51) propone unos requisitos fundamentales para la creación de un gran personaje: "el hallazgo de una fórmula (que el personaje ejercita todo el tiempo y en la que descansa -fatalmente- el mecanismo del chiste), una puntería ajustada en la estereotipia (la fórmula del personaje pone en acción un arquetipo social), la persistencia en el tiempo de una identidad (la fugacidad y el cambio suelen ser incompatibles con los grandes personajes consagrados)". Si esto es así, podríamos pensar a La mujer sentada como una suerte de antipersonaje. Aunque se la ha identificado como la personificación del sentido común más conservador (así la ha descripto Marilú Marini, por ejemplo), esta mujer quieta no presenta, fuera su apariencia sedente, características fijas. Asiste a un desfile de personajes (un caracol, un conejo, su pequeña hija o una criatura indefinible similar al Clemente creado por Caloi en $1973^{24}$ ) con los que sostiene diálogos que, cada vez, redefinen el perfil de ese personaje principal. Aunque se la ve siempre igual, en su posición casi invariable de una viñeta a otra, el requisito de la estereotipia no se cumple. La mujer sentada se modifica de modo radical de una tira a otra: según las historias, puede mostrarse pacata o evidenciar conductas tan heterodoxas como tener un hijo con un perro.

\footnotetext{
${ }^{22}$ César Aira, Copi (1991). Rosario, Beatriz Viterbo, 2003.

${ }^{23}$ Pablo De Santis(1998, p. 113). La historieta se definió como un género en EE.UU. a partir de la disputa por un público masivo entre los dos más grandes newspapermen -Joseph Pullitzer y William Randolph Hearst. Se considera a Yellow Kid como la primer tira cómica. Creada por Felton Outcault en 1893 para The New York World, fue plagiada poco después por el diario del otro magnate norteamericano. Para el año 1900 se había generalizado el suplemento dominical de comics de al menos cuatro páginas en colores. AA.VV, Bande dessinée et figuration narrative. Paris, Musée d'Arts Décoratifs - Société d'Etudes et de Recherches des Littératures Dessinées, 1967, p. 139.

${ }^{24}$ El parecido con el personaje de Caloi ha sido notado por Judith Gociol y Diego Rosemberg (2000, p. 223).
} 
Por ser un medio masivo, Le Nouvel Observateur implicaba ciertas limitaciones temáticas. La mujer sentada trata temas vinculados a la sexualidad, por ejemplo, pero no avanza en el repertorio transexual que anima la narrativa y dramaturgia de Copi. El impulso profanador (en el sentido que rescata Giorgio Agamben (2005), de restituir al libre uso ciertos objetos vedados) vibraba en las tiras de Copi de Le Nouvel Observateur. Pero en las tiras publicadas durante los años '70 en revistas para adultos de menor tirada como Charlie Mensuel o Hara Kiri, ese impulso tomó una inflexión procaz a tono tanto con los contenidos de esas publicaciones como con su propia producción literaria y teatral ${ }^{25}$. La revista Pilote, dirigida por René Goscinny, que publicaba tiras como Asterix, Le Petit Nicolas y Lucky Luke, resultaba un tanto infantil para los nuevos historietistas. La prolija documentación que registraban esas aventuras y el dibujo utilizado al servicio del guión eran desplazados por una búsqueda estética que en muchos casos prescindía de la claridad narrativa ${ }^{26}$. A mediados de los 70 , en cambio, entre las historietas de Willem, Wolinski, Isabelle Reiser o Cabu, y a la par las publicidades sarcásticas que conformaban los contenidos de Hara Kiri se insertaban los comic de Copi.

Imagen 3 - Tira reproducida en La femme assise. Paris, Stock, 2002..

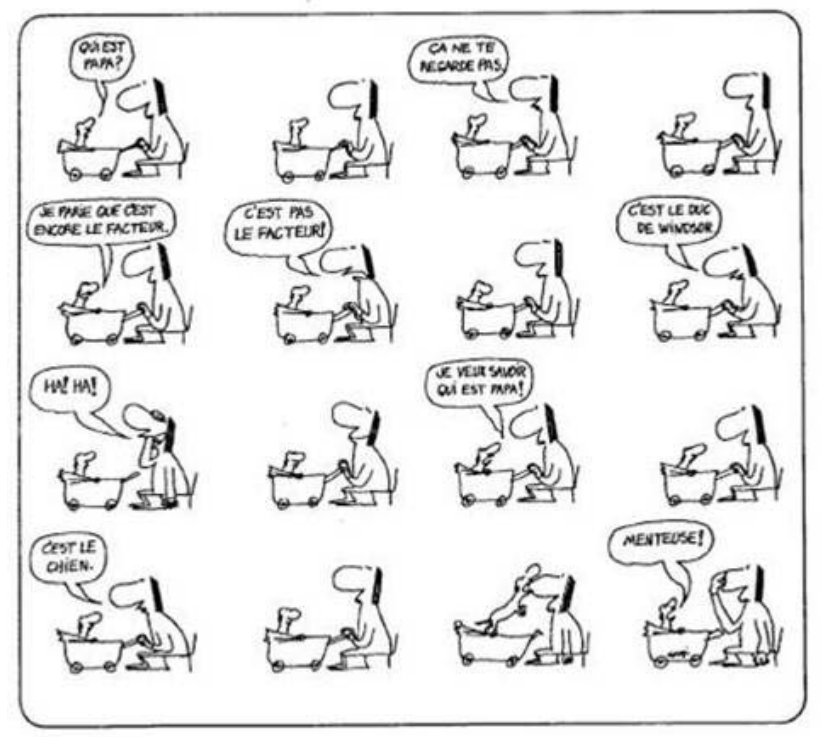

Fonte: Copi $\left(1968\right.$, p. 102-104). ${ }^{27}$

Los temas de estas historietas van desde el matrimonio entre una mujer blanca y un pigmeo llamado Kulotó que habla mal el francés, o un curso universitario vivencial de sexo oral dictado por la mujer sentada, hasta una domadora circense a quien los leones comieron los

\footnotetext{
${ }^{25}$ Muchas de estas tiras fueron compiladas en Francia en 1977, libro traducido por Anagrama en 1982. Copi, Les vieilles putes. Paris, Editions du Square, 1977. Mi gratitud a Daniel Link por estos materiales.

${ }^{26}$ Pablo de Santis, (1998).

27 - También forma parte de Los pollos no tienen sillas. Buenos Aires, Jorge Álvarez, 1968, pp. 102-104
} 
brazos y las piernas, o la declaración de amor de una anciana con sombrero y bastón a otra de su misma edad. A su vez, la estabilidad de la composición y el acabado que presentaba La mujer sentada en Le Nouvel Observateur se ve mellada por repeticiones imprecisas de una viñeta a otra. Estas tiras ofrecen a la vista un mundo de configuración precaria, como puede verse en "Kulotó" o "Recuerdos de circo" ${ }^{28}$, por ejemplo. Este aspecto desganado enfatiza -paradójicamente- el carácter corrosivo de los guiones y los diálogos.

\section{Interpelaciones de lo local: Amazonia como paraíso sexual.}

Los temas de algunas otras tiras publicadas en esos años dan una idea del lugar que tuvo un cierto repertorio de 'exotismos': la mencionada "Kulotó", donde este pequeño hombre africano se ve obligado por una mujer blanca a casarse con ella; "Las costumbres incas": la mujer sentada transformada en reina de los Incas pretende sacrificar a su hija de doce años; o "El sexo de los marcianos", donde un extraterrestre (lleva casco con antenas) pregunta con inocencia a la mujer: quién es el jefe de su planeta, qué es un marido, y si hace el amor con la cocina eléctrica ${ }^{29}$. Nos concentraremos en una historia en particular con el fin de indagar los sentidos que la figura de América Latina tomó durante estos años ${ }^{30}$. Nos referimos a "El paraíso de la hermana Sophie", publicada en Charlie en octubre de $1976^{31}$. Situada en la Amazonia, la historia está protagonizada por una novicia carmelita, Sophie, y un "indio", Tac Toc

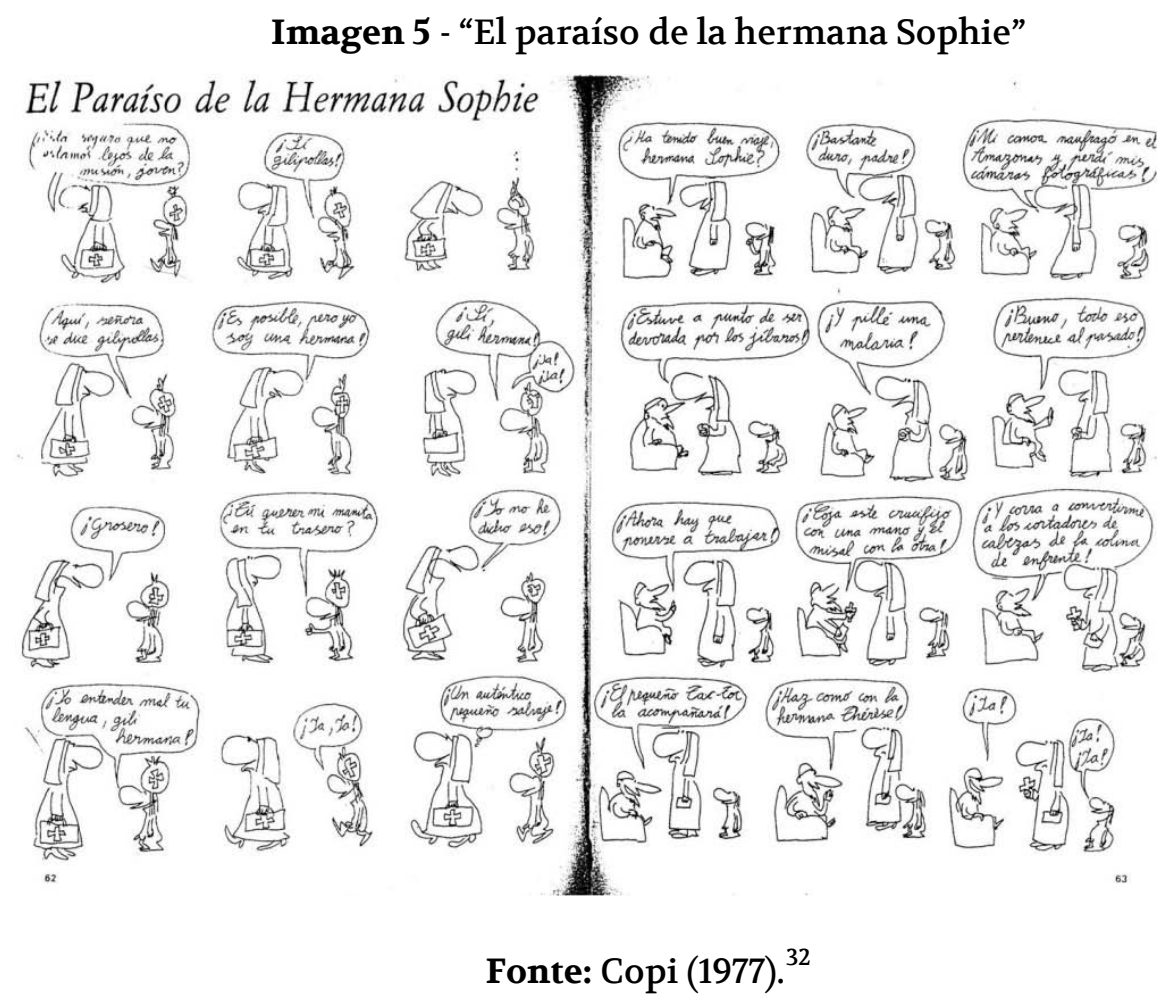

\footnotetext{
${ }^{28}$ Publicados respectivamente en Charlie n. 87, avril 1976; y Hara Kiri n.182 novembre 1976.

${ }^{29}$ Publicado en Hara Kiri de diciembre de 1975.

${ }^{30}$ Sobre la representación de América Latina en historietas durante la posguerra, véase Jacques Gilard (1992, p. 117-140).

${ }^{31}$ Reproducido en Copi (1982, p. 62-68).

32 - Les vieilles putes. Paris, Editions du Square, 1977. La tira se publicó por primera vez en Charlie n. 93, Paris, octobre 1976. El libro fue traducido por Anagrama en 1982 como Las viejas putas
} 
En la primer viñeta, Sophie camina con un maletín de enfermería en una mano, seguida por un personaje masculino desnudo y con una melena hasta los hombros (de menor tamaño que la mujer, como todos los personajes masculinos de Copi). “¿Está seguro que no estamos lejos de la misión, joven?", pregunta la hermana a Tac Toc, a quien unas viñetas más adelante ella tilda de "auténtico pequeño salvaje”. Al llegar, Sophie relata al fraile titular de la misión las peripecias por las que pasó a lo largo de su camino por la selva: su canoa naufragó en el Amazonas, casi fue devorada por los jíbaros y se contagió malaria. El fraile desestima estos inconvenientes y le ordena que comience con su trabajo: convertir a los indios. Cuando la novicia se resiste a cumplir la orden de ir de inmediato a catequizar a los cortadores de cabeza de en frente, el monje la amenaza con torturarla con una tenaza caliente. Tac Toc -uno de los 40 hijos que el fraile ha tenido con su harén- acompaña a la novicia carmelita Sophie para que lleve a cabo esa tarea.

En medio de la selva (de la que no hay indicios dibujados), Tac Toc la deja sola. Aparece luego disfrazado de "cortador de cabezas", con una flecha en la mano, una pluma en la cabeza y una pintura facial consistente en una línea zigzagueante sobre su gran nariz. Sophie no lo reconoce y Tac Toc le dice, en su francés estilo Tarzán, que está dispuesto a convertirse si ella se casa con él. Sophie accede luego de escuchar a Dios ordenarle que contraiga matrimonio (en verdad, los indios son ventrílocuos). En el siguiente recuadro se ve a Sophie sin su hábito de monja en una choza esperando a su marido luego de la ceremonia. Lleva la misma pintura facial que Tac Toc, y el cabello y los senos a la vista. “Rápido, al catre!”, ordena Tac Toc en la viñeta que sigue. Un dibujo los muestra copulando y, esa noche, la última oración de la novicia es "Qué bien".

En la viñeta siguiente Sophie despierta en su celda, en el Carmelo, con su hábito, su misal y su cruz. El viaje a Amazonia no fue 'real': “HHe pecado en sueños!”, desespera. A fuerza de oración y penitencia, la novicia olvida su sueño pecaminoso. Sin embargo, 50 años más tarde Sophie lleva estigmas: sus manos sangran. En una serie de viñetas, la monja conversa con uno de los periodistas que vienen de todo el mundo a verla. Los recuadros recuperan la estructura de $L a$ mujer sentada, en este caso una religiosa, que mantiene un diálogo con una suerte de pollo con anteojos y bloc de notas. Ella espera ser canonizada pronto. Con lágrimas en los ojos, en la última viñeta Sophie pregunta al periodista: “¿Es verdad que el Paraíso se parece a la Amazonia?”.

Esta historia humorística pone en juego una serie superpuesta de imaginarios y cuestiones de actualidad promediando los años '70. Por un lado, retoma uno de los equívocos que el heterogéneo territorio latinoamericano fue acumulando a lo largo de su historia; la idea de América como el paraíso terrenal de los primeros conquistadores españoles (MONTALDO, 2000). Pero el paraíso de la religiosa Sophie es carnal. A su vez, la tira parodia la actividad catequizadora de los carmelitas misioneros en la Amazonia, que tomó un sesgo renovado ligado a la teología de la liberación hacia 1971 a partir del Concilio Vaticano II (1962-1965) y la Conferencia de Medellín $(1968)^{33}$. Copi ponía en obra una profunda desconfianza a la actividad catequizadora, ya sea

\footnotetext{
${ }^{33}$ Luis Luciniano (1994). En Brasil, según la repartición establecida entre las órdenes religiosas (1693), a los carmelitas les correspondía el Alto Amazonas a partir de São José de Río Negro (actual Manaus). (OLIVEIRA; HERNANDEZ, 2011).
} 
política o religiosa: pretender convertir a la Amazonia en otra cosa resultaba una tarea absurda. Los habitantes locales de la tira, por otra parte, no se dejan engañar con facilidad.

La historieta también incorpora el topos de la tortura en América Latina, que sobre la que circulaba información en Francia y era tematizado por agrupaciones como Amérique Latine NonOfficielle o el Grupo Denuncia. Además, la violencia física por parte de la autoridad constituía materia prima para el sarcasmo del humor grafico de esos años en su afán por profanar el imaginario de la corrección política francesa. Uno de los ejemplos más extremos tal vez sea una falsa publicidad que Hara Kiri publicó en febrero de 1974: la imagen fotográfica de un hombre atado a una silla a quien un militar con uniforme de estampado camuflado le arranca la uñas de una mano con una tenaza mientras una mujer le lima las uñas de la otra mano. La leyenda de esta parodia publicitaria versa:

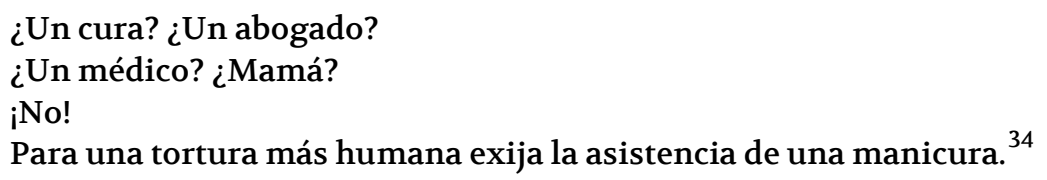

La imagen de esta escena cruenta muestra algunos rasgos de verosimilitud fuera del mismo dispositivo fotográfico, tales como la sangre que emana de las manos lastimadas de la víctima, pero se reconoce con facilidad como una escena ficticia producida para la revista. En el caso de la tira de Copi, la violencia no aparece como acción representada sino como amenaza. El aspecto caricaturesco de los personajes, por otra parte, contribuye a un efecto más humorístico y menos sarcástico.

La Amazonia también formaba parte del imaginario erótico. Gabriela Nouzeilles se refiere al retorno a lo primitivo como "puerta de acceso a lo masculino" en relación con la práctica del viaje y el turismo, y a la preeminencia de dos zonas geográficas consideradas como manifestaciones extremas de lo natural: la selva y el desierto: "Con la aceleración de la modernización y la globalización en la segunda mitad del siglo XIX, la Patagonia junto con la Amazonia se fueron perfilando como uno de los últimos refugios naturales en el globo donde la aventura todavía era posible" (NOUZEILLES, 2002). Flavio Rapisardi y Alejandro Modarelli describen una modulación gay de la fantasía erótica del trópico y de Brasil como paraíso sexual; un universo utópico presente, por otra parte, en La guerra de los putos (1982), la novela de Copi protagonizada por la sensual hermafrodita Conceição do Mundo ${ }^{35}$.

Brasil fue -es- una 'geografía imaginaria', un espacio poetizado, sobre el que se articula un repertorio cultural que circula entre las

\footnotetext{
${ }^{34}$ Hara Kiri n.149, février 1974, p. 23.

${ }^{35}$ Copi (1982).
} 
locas porteñas: sexo, masculinidad, pobreza, instinto y desprejuicio. [...] Si nos atenemos al imaginario que se creó sobre Brasil, deberíamos aceptar que su libertad fue en expansión, hasta lograr el dibujo exacto del 'paraíso gay'. ${ }^{36}$

Estos autores mencionan a París en tanto "la estación pedagógica" donde la homofobia era menos violenta que en Buenos Aires. En este sentido, recordemos que en 1972 el filósofo Guy Hocquenghem (amigo de Copi) comunicó públicamente su homosexualidad en las páginas de Le Nouvel Observateur y animó la creación del Front Homosexuel d'Action Révolutionnaire (FHAR) ${ }^{37}$.

Por último, los primeros años '70 vieron el auge de la Amazonia como punto neurálgico concerniente a los peligros ambientales. Si bien los estudios científicos sobre los vínculos entre los diversos componentes biológicos en ambientes naturales y definición de la ecología en tanto disciplina específica data de mediados del siglo XIX y tuvo avances importantes en los años ' $50^{38}$, fue a comienzos de la década del '70 que estos temas adquirieron difusión masiva. En 1970 se celebró en los Estados Unidos por primera vez el "día de la tierra". Ese mismo año, Tomás Maldonado publicó en Milán su libro Ambiente humano e ideología: notas para una ecología crítica, que fue traducido al francés y al castellano en $1972^{39}$.

En efecto, 1972 no sólo fue el año en que Hocquenghem salió del closet en Le Nouvel Observateur. También fue un año clave en la divulgación mediática de conflictos ambientales en Francia. Ese mismo periódico editó el libro Ecología y revolución, con textos de Herbert Marcuse, Edgar Morin, entre otros. La Amazonia tuvo una presencia creciente en la prensa francesa: notas sobre la construcción de la ruta transamazónica denunciando los efectos drásticos de este emprendimiento sobre la vida de diversas tribus indígenas ${ }^{40}$, sobre los problemas de la explotación petrolera, la concentración de la propiedad de la tierra y la desforestación en esa región ${ }^{41}$. Gabriela Nouzeilles (2002, p. 19) afirma que, además de proveedora de productos 'naturales', América Latina ofrece escenarios apropiados para fantasear la huida de un mundo demasiado tecnologizado, el escape de la alienación urbana. Si en el imaginario francés, Amazonia se constituyó en un lugar fascinante ajeno a la civilización, en Copi el espacio de la selva no representa una reserva natural que debía mantenerse intacta sino un catalizador de la profanación cultural. Parodiando la "fantasía escapista", Copi sitúa en Amazonia una suerte de

\footnotetext{
${ }^{36}$ Flavio Rapisardi y Alejandro Modarelli (2001, p. 130-131). Sobre el imaginario sexual vinculado al Brasil, véase también Richard Parker (1991).

37 Frédéric Martel (1999, p. 13-14). Según este autor, Anti-Edipo (1972) de Deleuze y Guattari fue crucial para la liberación sexual. Libido y revuelta fueron combinables luego de mayo del '68.

38 El término fue definido por el zoólogo alemán Ernst Haeckel. El primer libro de Eugene y Howard Odum, Fundamentals of Ecology (1953), fue un texto central para la disciplina durante unos diez años. Una obra posterior, Environment, Power and Society (1971) da cuenta del giro participativo y de la lectura en términos de poder de los conflictos ambientales. 39 Por la Union générale d'éditions en París, y por Nueva Visión en Buenos Aires.

40 Barnes (1972, p. 33). Con esta autopista de $5000 \mathrm{~km}$ iniciada en 1964 se proyectaba unir la costa noreste del Brasil con la frontera con Perú.

41Vanhecke (1975), Gaillard (1979), Lewis (1979).
} 
arcadia sexual donde la generosa naturaleza tropical incorpora a los sujetos a su proliferación vital.

\section{Referências}

AGAMBEN, Giorgio. Elogio de la profanación. Profanaciones, Buenos Aires, p. 97-119, 2005.

ALVARADO, M.; ROCCO-CUZZI, R. Primera Plana: el nuevo discurso periodístico de la década del '60. Punto de Vista, Buenos Aires, n. 22, p. 27-30, Dic. 1984.

BARNES, John. Brésil. L’autoroute qui toue. Le Nouvel Observateur, n. 402, p. 33, jul. 1972.

BARTHES, Roland. El nuevo Citroën. In: Mitologías. Buenos Aires: Siglo XXI, 2003. pp. 154-156.

COPI. La guerre des pédés. Paris: Albin Michel, 1982.

COPI. Las viejas putas. Barcelona: Anagrama, 1982.

COPI. Le bal des folles. Paris: Christian Bourgois, 1977.

COPI. Preface pour Río de la Plata. In: DAMONTE, Jorge (Comp.) Copi. Paris: Christian Burgois, 1990. p. 81-91.

COPI. Une langouste pour deux. Paris: Christian Bourgois, 1978.

COPI. Nouvel Observateur n. 189, 26 juin- 2 juillet 1968, p. 29.

COUSTÉ, Alberto. El triunfo de la literatura dibujada. Primera Plana, Sonora, n. 303, p. 44-49, 1968.

DE SANTIS, Pablo. La historieta en la edad de la razón. Buenos Aires: Paidós, 1998.

DELEUZE, Pilles; GUATTARI, Felix. Kafka: por una literatura menor. México: Era, 2001.

ESSLIN, Martin. El teatro del absurdo. Barcelona: Seix barral, 1966.

FRANCO, Marina. El exilio: argentinos en Francia durante la dictadura. Buenos Aires: Siglo XXI, 2008.

GAILLARD, Pierre. L'empire privé du Rio Jari au Brésil. Le Matin. Suplément, n. 843, p. 12-13, nov. 1979.

GILARD, Jacques. Utopies hebdomadaires: l'amerique latine des bandes dessinés. Caravelle, Toulouse, n. 58, p. 117-140, 1992.

GOCIOL, Judith; ROSEMBERG, Diego. La historieta argentina: una historia. Buenos Aires: Ediciones La Flor, 2000.

HOSBAWM, Eric. Historia del siglo XX. Buenos Aires: Crítica, 1998. 
LEWIS Norman. The burning of the trees. How the rape of Amazonia could ruin life on earth. New Observer, p. 46, 51-59, abr. 1979,

LINK, Daniel. Clases: literatura y disidencia. Buenos Aires: Norma, 2005.

LINK, Daniel. La loca y las formas. Revista Ñ, Buenos Aires, n. 382, Ene. 2011.

LINK, Daniel. Santa Copi. Página 12. Suplemento Soy, Junio 2008. Disponible en: <http://www.pagina12.com.ar/diario/suplementos/soy/1-115-2008-06-06.html $>$. Aceso en: 20 out. 2011.

LUCINIANO, Luis. La Misión Carmelita en Sucumbíos. Quito: Abya-yala, 1994.

MARTEL, Frédéric. The pink and the black: homosexuals in Paris since 1968. Stanford: Stanford University Press, 1999.

MASOTTA, Oscar. La historieta en el mundo moderno. Buenos Aires: Paidós, 1969.

MONTALDO, Graciela. Ficciones culturales y fábulas de identidad en América Latina. Rosario: Beatriz Viterbo, 2000.

NOUZEILLES, Gabriela (Comp.). La naturaleza en disputa: retóricas del cuerpo y el paisaje en América Latina. Buenos Aires: Paidós, 2002.

OLIVEIRA, Myriam Andrade Ribeiro de; HERNÁNDEZ, Mariela Brazón. La epopeya jesuítica en el amazonas brasilero $y$ sus imágenes. Disponible en:<www.upo.es/depa/ webdhuma/areas/arte/actas/3cibi/ documentos/41f.pdf >. Aceso en: nov. 2011.

PARKER, Richard. Bodies, pleasures and passions: sexual culture in contemporary Brazil. Beacon: Boston, 1991.

PAULS, Alan. Lino Palacio: la infancia de la risa. Buenos Aires: Espasa-Calpe, 1995.

PELLETTIERI, Osvaldo (Ed.). De Sarah Bernhardt a Lavelli: Teatro francés y teatro argentino (1890-1990). Cuaderno del GETEA, Buenos Aires, n. 3, 1993.

PLANTE, Isabel. La multiplicación (y rebelión) de los objetos: Julio Le Parc y la consagración europea del arte cinético. In: PLANTE, Isabel; ROSSI, Cristina. XIII Premio fundación telefónica a la investigación en historia de las artes plásticas en la Argentina: la abstracción en la Argentina: siglos XX y XXI. Buenos Aires: Fundación Espigas, 2010.

PODLUBNE, Judith; GIORDANO, Alberto. Exilio y extraterritorialidad: Wilcock y Bianciotti. In: DRUCAROFF, Elsa. Historia crítica de la literatura argentina 11: la narración gana la partida. Buenos Aires: Emecé, 2000. p. 321-341.

RAPISARDI, Flavio; MODARELLI, Alejandro. Fiestas, baños y exilios los gays porteños en la última dictadura. Buenos Aires: Sudamericana, 2001.

ROSS, Kristin. Fast cars, clean bodies: decolonization and reordering of French culture. Massachussets: MIT Press, 1995. 
SONTAG, Susan. Notes On 'Camp'. 1964. Disponible en: $<$ http://interglacial.com/ sburke/pub/prose/Susan_Sontag_-_Notes_on_Camp.html>. Acceso en: 21 out. 2011.

STEIMBERG, Oscar. La nueva historieta de aventuras; una fundación narrativa. In: DRUCAROFF, Elsa. Historia crítica de la literatura argentina: La narración gana la partida. Buenos Aires: Emecé, 2000. p. 533-548.

STEIMBERG, Oscar. Leyendo historietas: estilos y sentidos en un arte menor. Buenos Aires: Nueva Visión, 1977.

STEIMBERG, Oscar. Sobre algunos temas y problemas del análisis del humor gráfico. In: . Signo y seña. Buenos Aires: UBA, 2001.

TCHERKASKI, José. Habla Copi. Homosexualidad y creación. Buenos Aires: Galerna, 1998.

TERÁN, Oscar. Nuestros años sesenta. Buenos Aires: El cielo por asalto, 1993.

VANHECKE, Charles. Matto-Grosso, western brésilien. Le Monde, p. 1-5, fev.1975.

VÁZQUEZ LUCIO, Oscar E. El boom de Landrú. In: . Historia del humor gráfico y escrito en la Argentina. Buenos Aires: Eudeba, 1985.

VÁZQUEZ, Laura. El oficio de las viñetas: la industria de la historieta argentina. Buenos Aires: Paidós, 2010.

Recebido em 30/02/2012

Aprovado em 30/05/2012 